\title{
Treatment patterns, health state, and health care resource utilization of patients with radioactive iodine refractory differentiated thyroid cancer
}

This article was published in the following Dove Press journal:

Cancer Management and Research

30 May 2016

Number of times this article has been viewed

\author{
Andrew G Gianoukakis' \\ Natalia M Flores ${ }^{2}$ \\ Corey L Pelletier ${ }^{3}$ \\ Anna Forsythe ${ }^{3}$ \\ Gregory R Wolfe ${ }^{2}$ \\ Matthew H Taylor ${ }^{4}$ \\ 'Division of Endocrinology and \\ Metabolism, Harbor-UCLA Medical \\ Center, The University of California, \\ Los Angeles, ${ }^{2} \mathrm{Health}$ Outcomes \\ Research, Kantar Health, Foster City, \\ $\mathrm{CA},{ }^{3} \mathrm{Global}$ Value and Access, Eisai, \\ Inc., Woodcliff Lakes, NJ, ${ }^{4}$ Division of \\ Hematology and Medical Oncology, \\ Oregon Health and Science University, \\ Portland, OR, USA
}

Background: Patients with differentiated thyroid cancer (DTC) often respond well to treatment but some become refractory to radioactive iodine (RAI) treatment, and treatment options are limited. Despite the humanistic and economic burden RAI refractory disease imposes on patients, published research concerning treatment patterns and health care resource utilization is sparse.

Methods: Data were collected from an online retrospective chart review study in the US and five European Union (EU) countries (France, Germany, Italy, Spain, and UK) with physicians recruited from an online panel. Physicians $(\mathrm{N}=211)$ provided demographics, disease history, treatment information, and health care resource utilization for one to four of their patients with radioactive iodine refractory differentiated thyroid cancer (RR-DTC).

Results: The majority of the patients with RR-DTC (N=623) were female (56\%), and their mean age was 58.2 years. In this sample, $63.2 \%$ had papillary thyroid cancer and $57.0 \%$ were in Stage IV when deemed RAI refractory. Patients with RR-DTC experienced regional recurrence in the thyroid bed/central neck area (25.3\%) and had distant metastatic disease (53.6\%). At the time data were collected, $50.7 \%$ were receiving systemic treatment. Of those, $78.5 \%$ were on first-line treatment and $62.7 \%$ were receiving multikinase inhibitors. Regional differences for prescribed treatments were observed; the US was more likely to have patients receiving multikinase inhibitors (79.2\%) compared with UK (41.2\%) and Italy (17.1\%). Additional details regarding treatment patterns and resource utilization are discussed.

Conclusion: The current study aimed to obtain a greater understanding of RR-DTC treatment globally. These results can assist in the development and implementation of treatment guidelines and ultimately enhance the care of patients with RR-DTC.

Keywords: thyroid cancer, disease burden, therapy options, cost of illness

\section{Introduction}

A substantial number of individuals are diagnosed with thyroid cancer worldwide, including 62,450 in the US in 2015 and 52,937 in Europe in 2012; 1,950 and 6,336 annual deaths are attributable to this disease in these regions, respectively. ${ }^{1,2}$ The majority of individuals with thyroid cancer are diagnosed with differentiated thyroid cancer (DTC) with either papillary or follicular carcinoma, which represents $93 \%$ of all thyroid cancers. ${ }^{3}$ Empirical evidence suggests that the incidence of this disease is increasing globally across all tumor sizes and stages. ${ }^{4}$ Additionally, thyroid cancer mortality is slightly increasing, despite earlier detection and diagnosis. ${ }^{4}$

The majority of patients diagnosed with DTC respond well to treatment and have an excellent prognosis, with 5-year survival rates in excess of $90 \%$ across all stages. ${ }^{5}$
Correspondence: Natalia M Flores Health Outcomes Research, Kantar Health, 393 Vintage Park Drive, Suite 100, Foster City, CA 94404, USA $\mathrm{Tel}+\mathrm{I} 6504037057$

Email natalia.flores@kantarhealth.com (c) 17 (2) 2016 Gianoukakis et al. This work is published and licensed by Dove Medical Press Limited. The full terms of this license are available at https://www.dovepress.com/
terms.php and incorporate the Creative Commons Attribution - Non Commercial (unported, v3.0) License (http://(reativecommons.org/licenses/by-nc/3.0/). By accessing the work you hereby accept the Terms. Non-commercial uses of the work are permitted without any further permission from Dove Medical Press Limited, provided the work is properly attributed. For permission for commercial use of this work, please see paragraphs 4.2 and 5 of our Terms (https://www.dovepress.com/terms.php). 
Standard treatment for DTC includes surgical excision and is frequently combined with adjuvant radioactive iodine (RAI) treatment. ${ }^{6}$ However, $~ 5 \%$ of patients with DTC can become refractory to radioactive iodine (RR-DTC) treatment. ${ }^{7}$ In these circumstances, prognosis is poor, and treatment options are limited. ${ }^{3}$

Some new oral multikinase inhibitors (MKIs) have recently been developed and approved by US Food and Drug Administration (FDA) and European Medicines Agency (EMA) for the treatment of patients with metastatic RRDTC. For example, sorafenib was approved by the FDA and EMA for the treatment of this disease in 2013 and 2014, respectively. This targeted MKI was shown to halt disease progression in Phase II and III clinical trials and was the first agent approved for RR-DTC in nearly four decades. ${ }^{8,9}$ In the large Phase III DECISION trial, treatment with sorafenib resulted in an overall response rate (complete response plus partial response) of $12.2 \%$ and a median progression-free survival of 10.8 months compared with 5.8 months in the placebo arm. ${ }^{9}$ Lenvatinib was approved by FDA in early 2015 for the treatment of patients with locally recurrent or metastatic, progressive, and RR-DTC and has received EMA approval in 2015 for the treatment of adult patients with progressive (papillary/follicular/Hürthle cell) RR-DTC. In the large Phase III SELECT trial, lenvatinib demonstrated an overall response rate (complete response plus partial response) of $64.8 \%$ and a median progressionfree survival of 18.3 months compared with 3.6 months in the placebo arm. ${ }^{10}$

While more successful treatment options have recently been approved, broader challenges still exist in the treatment of RR-DTC, with debate surrounding the criteria for defining refractory disease ${ }^{11}$ and what constitutes optimal medical management for this patient group. ${ }^{3,12-14}$ There is limited published research regarding the characteristics of patients with RR-DTC, with the majority of knowledge stemming from clinical study samples. Research using more comprehensive patient sampling has yet to be published. Brose et $\mathrm{al}^{15}$ noted the additional challenge of creating uniform treatment guidelines for patients with RR-DTC, citing the limited clinical trial information available, and the varying quality and availability of data from country to country. Important differences in treatment patterns may exist regionally and internationally, and thus global data are critical to help guide policy and treatment guideline efforts.

Furthermore, limited information exists regarding humanistic and economic burdens imposed by RR-DTC, ${ }^{16}$ as emphasized by Anderson et $\mathrm{al}^{3}$ in a recent systematic review. Gallop et al ${ }^{17}$ recently employed a qualitative psychometric study design to examine the impact of DTC among 52 patients. The authors noted that impairments in quality of life were widely reported by patients, particularly among those with RR-DTC. As few of the patients in this sample were diagnosed with RR-DTC, this study highlights the need for research in this patient population. Further work was undertaken by the current authorship group to develop health-related quality of life weights for RR-DTC health states, a critical step to effectively evaluate treatment benefit among this patient group. ${ }^{18}$

Despite the burden imposed by RR-DTC, its poor prognosis and debate concerning optimal treatment, there exists a paucity of published research pertaining to treatment patterns and health care resource utilization among this group. The current study seeks to begin to address this gap in the literature and provide unique and important insight into the treatment of patients diagnosed with RR-DTC in the US and Europe and to highlight potential regional differences. Utilizing representative sampling and rigorous methodology, this study investigates treatment patterns and health care resource utilization of this patient group, with emphasis given to potential regional differences that emerge between the US and five European Union countries: France, Germany, Italy, Spain, and UK (EU5).

\section{Materials and methods \\ Sample}

The study was reviewed and approved by the Essex institutional review board, Lebanon. All online respondents agreed to the statement of informed consent before proceeding. Those who agreed to participate were then entered into the study. Data were collected by performing a retrospective chart review in the US and EU5 countries with physicians recruited from an online panel in Spring 2014. Physicians ( $N=211$ [US, $n=89$ and EU5, $n=24-25$ from each country]) provided clinical information on one to four of their patients with RR-DTC in an online survey. Physicians were asked to provide information on patients with RR-DTC whom they were currently managing or managed until they were deceased. Physicians, who qualified for the study, were financially compensated for their participation.

The majority of physicians recruited to the study were mid-career (aged 35-54 years), male, and reported working primarily in group-based oncology/hematology clinical settings. Providers reported spending the majority of their time engaged in direct patient care, with nearly half practicing in nonacademic or private practice settings. On average, 
providers reported treating 85 patients with DTC and 51 with RR-DTC annually with $62 \%$ of patients with RR-DTC having papillary thyroid cancer and $38 \%$ having follicular thyroid cancer.

\section{Measures}

Demographics, disease history, treatment information, and health care resource utilization over the previous 12 months were included and reported descriptively for each patient.

\section{Demographics and disease history}

Patient information pertaining to sex, age, country (US, UK, Spain, Italy, Germany, or France), disease history, tumor histology at DTC diagnosis, Eastern Cooperative Oncology Group score, American Joint Committee on Cancer/European Network for the Study of Adrenal Tumors (AJCC/ENSAT) staging, and disease state (objective tumor response, stable disease, and progressive disease) were collected for all patients. Additionally, whether the thyroid cancer metastasized, sites of metastases, and locations of regional recurrence were reported.

\section{Treatment patterns}

Physicians categorized their patients with RR-DTC as follows: watch and wait $(\mathrm{WW})(\mathrm{n}=130)$ or active treatment $(n=493)$. Physicians categorized patients as WW during a time in which they were being actively monitored but cancer-specific treatment was not administered. Active treatment was further subdivided as follows: nonsystemic management $(n=177)$ and systemic treatment $(n=316)$. Those in nonsystemic management were considered to be under active treatment by their physicians but had not yet received systemic treatment (eg, treatment regimen such as chemotherapy) and/or had only received local therapy (eg, external beam radiation) or thyroid-stimulating hormone suppression therapy. Information concerning treatment patterns was only collected for those who had received systemic treatment (availability for certain medications, eg, sorafenib, varies by region). Medication by line of therapy was reported for cytotoxic chemotherapies and MKIs subsequently (medications per line are not mutually exclusive as some physicians reported giving more than one medication per line):

- Cytotoxic chemotherapy: doxorubicin-based therapy (including doxorubicin monotherapy, doxorubicin-based combination therapies, and liposomal doxorubicin), cisplatin-, docetaxel-, and paclitaxel-based therapies (including paclitaxel and nab-paclitaxel), etoposide, and other chemotherapy drugs.
- MKIs: sorafenib, sunitinib, vandetanib, cabozantinib, pazopanib, axitinib, and other MKIs.

\section{Adverse events and symptoms of disease burden}

Adverse events (eg, nausea and vomiting, loss of appetite, and hair loss) were assessed for each treatment class (ie, chemotherapies and MKIs) and symptoms of disease burden (eg, bone pain, constant cough, or swelling in the neck) unrelated to treatment.

\section{Health care resource utilization}

Health care resource utilization was assessed based on frequency of four different forms of health care resources over the past 12 months: office visits with current physician in the past 12 months, total number of doctor visits that includes the current physician and other physicians in the past 12 months, number of hospitalizations in the past 12 months due to disease-associated or treatment-associated side effects, and total days hospitalized. Total days hospitalized will be reported for disease-associated or treatment-associated side effects as well.

\section{Analyses}

Descriptive statistics were conducted to describe all study measures. Percentages are reported for categorical variables, and means and standard deviations are reported for continuous variables. Bivariate analyses (chi-square tests) were then conducted to assess how treatment or management type differed by country. Pairwise comparisons used the Bonferroni correction when comparing country differences (eg, US vs France). One-way analysis of variances were also conducted to examine resource utilization by the number of symptoms as a result of disease burden (ie, one symptom vs two or more) and resource utilization by disease state.

\section{Results}

\section{Demographics and disease history}

A total of 623 patient charts were collected in the study (US, $n=268$; UK, $n=72$; Spain, $n=70$; Italy, $n=70$; Germany, $\mathrm{n}=72$; and France, $\mathrm{n}=71$ ). Over half of patients included in the current study were female (56\%), and the average age was 58.2 years.

Patients were initially diagnosed with Stage II (29.1\%) or III (27.1\%) DTC and had histology of papillary thyroid cancer (63.2\%). However, over half of the patient population had Stage IV disease $(57.0 \%)$ by the time it was deemed refractory and over half the patient population had an Eastern Cooperative Oncology Group score of 1 (54.0\%) (Table 1). 
Table I Patient characteristics for all patients with RR-DTC $(\mathrm{n}=623)$

\begin{tabular}{|c|c|}
\hline Patient characteristics & $\%(n=623)$ \\
\hline \multicolumn{2}{|l|}{ Stage of DTC at diagnosis } \\
\hline Stage I & 11.7 \\
\hline Stage II & 29.1 \\
\hline Stage III & 27.1 \\
\hline Stage IV & 32.2 \\
\hline \multicolumn{2}{|l|}{ Tumor histology at DTC diagnosis } \\
\hline Papillary thyroid cancer (PTC) (including all subtypes) & 63.2 \\
\hline Follicular thyroid cancer (FTC) & 36.8 \\
\hline \multicolumn{2}{|l|}{ Stage of the patients DTC deemed refractory } \\
\hline Stage I & 8.5 \\
\hline Stage II & 19.3 \\
\hline Stage III & 15.2 \\
\hline Stage IV & 57.0 \\
\hline \multicolumn{2}{|l|}{$\begin{array}{l}\text { Patients ECOG performance score prior to most recent } \\
\text { therapy (not asked of those in watch and wait) }\end{array}$} \\
\hline 0 - asymptomatic & 20.1 \\
\hline I - symptomatic but completely ambulatory & 54.0 \\
\hline 2 - symptomatic, $<50 \%$ in bed during the day & 22.1 \\
\hline 3 - symptomatic, $>50 \%$ in bed, but not bedbound & 3.4 \\
\hline 4 - bedbound & 0.4 \\
\hline Regional recurrence in bed/central neck area & 25.2 \\
\hline Metastatic disease & 53.6 \\
\hline \multicolumn{2}{|l|}{ Site of metastasis } \\
\hline Bones & 44.0 \\
\hline Brain & 2.4 \\
\hline Lymph nodes & 51.2 \\
\hline Lungs & 67.7 \\
\hline Skin & 2.4 \\
\hline Other & 1.5 \\
\hline \multicolumn{2}{|l|}{ Symptoms as a result of disease burden } \\
\hline Swelling/lump in the neck & 39.2 \\
\hline Pain in the front of the neck & 19.3 \\
\hline Pain at the ears & 8.7 \\
\hline Hoarseness or voice changes that do not go away & 19.6 \\
\hline Trouble swallowing & 23.3 \\
\hline Trouble breathing & 16.1 \\
\hline Constant cough not due to cold & 18.1 \\
\hline Bone pain & 23.3 \\
\hline
\end{tabular}

Abbreviations: RR-DTC, radioactive iodine refractory differentiated thyroid cancer; DTC, differentiated thyroid cancer; ECOG, Eastern Cooperative Oncology Group.

Approximately a quarter $(25.2 \%)$ of the patients had regional recurrence in the thyroid resection bed/central neck area. Slightly over half of patients sampled had thyroid cancer that had metastasized (53.6\%), primarily with involvement of the lungs (67.7\%), lymph nodes (51.2\%), and bone (44.0\%; Table 1). Table S1 shows the medications broken down by metastatic disease status.

Symptoms as a result of disease burden were reported for each patient with slightly more than half (56.5\%) of the patients reporting one symptom and the remainder (43.5\%) reporting two or more symptoms. The most common symptoms were swelling/lump in the neck (39.2\%), trouble swallowing $(23.3 \%)$, and bone pain $(23.3 \%)$ (Table 1).

\section{Treatment patterns}

Overall, approximately half of sampled patients were being treated with systemic treatment $(50.8 \%)$ with the remainder managed by WW (20.9\%) and nonsystemic management options (28.4\%). Significant differences emerged by region for those on systemic treatment: for example, $33.5 \%$ were on systemic treatment in Germany versus $59.3 \%$ in the US $(P<0.05$; Table 2$)$.

Information concerning treatment patterns was collected for those currently on systemic treatment $(n=316)$, with $32.3 \%$ of all patients treated with cytotoxic chemotherapies $(n=102)$ and $62.7 \%$ with MKIs $(n=198$; Table 3$)$. The remaining 5\% $(\mathrm{n}=16)$ were on other treatments (eg, BRAF inhibitors) but had received prior chemotherapies or MKIs (due to the small sample size of those on "other treatments," they will be included when reporting descriptives of treatment history but will not be included when comparing differences between systemic treatment types, eg, chemotherapies vs MKIs). Differences in regions emerged such that the UK and Italy had more patients on chemotherapies than the US $(P<0.05)$; the US and Spain had more patients on MKIs than the rest of the EU5 $(P<0.05)$; and Italy had the highest percent of patients on BRAF inhibitors $(P<0.05)$.

Of those on systemic treatment, MKIs were the most commonly prescribed treatment with sorafenib (43.4\%) and sunitinib (22.5\%). Cytotoxic chemotherapies were also common, most notably doxorubicin-based therapy (29.1\%), cisplatin-based therapy (13.3\%), and paclitaxel-based therapy (12.3\%).

Physicians from the EU5 were more likely to report the use of chemotherapy agents (such as doxorubicin-based therapy and cisplatin, both $P_{\mathbf{S}}<0.001$ ), while MKIs were more commonly used in the US (such as sorafenib, vandetanib, and cabozantinib, $\left.P_{\mathbf{S}}<0.001\right)$. Considerable regional variation emerged in medication usage throughout Europe. For chemotherapy drugs, this was most notable in rates of doxorubicin-based therapy ( $\mathrm{UK}=55.9 \%$ vs Spain $=28.1 \%$ ) and cisplatin (Italy $=40.0 \%$ vs Germany $=12.5 \%$ ). There were also differences among MKI use such as sorafenib (Spain $=50.0 \%$ vs Italy $=20 \%$ ) and sunitinib (Spain $=37.5 \%$ vs UK $=11.8 \%$; Table 4 ). The numbers reported in Table 4 are for medications administered over the course of treatment, thus collapsed across lines.

\section{Lines of therapy}

The majority of patients on systemic treatment were on first-line therapy $(78.5 \%)$ with $16.8 \%$ on second line and the remaining patients $(4.7 \%)$ on the third- or fourth-line therapy. 
Table 2 Current treatment or management type for all patients with RR-DTC by country $(n=623)$

\begin{tabular}{|c|c|c|c|c|c|c|c|}
\hline \multirow{2}{*}{$\begin{array}{l}\text { Current treatment or } \\
\text { management type }\end{array}$} & \multicolumn{6}{|c|}{ Survey country } & \multirow[t]{2}{*}{$P$-value } \\
\hline & $\begin{array}{l}\text { US } \\
(n=268) \\
(\%)\end{array}$ & $\begin{array}{l}\text { UK } \\
(n=72) \\
(\%)\end{array}$ & $\begin{array}{l}\text { Spain } \\
(n=70) \\
(\%)\end{array}$ & $\begin{array}{l}\text { Italy } \\
(n=70) \\
(\%)\end{array}$ & $\begin{array}{l}\text { Germany } \\
(n=72) \\
(\%)\end{array}$ & $\begin{array}{l}\text { France } \\
(n=7 I) \\
(\%)\end{array}$ & \\
\hline Watch and wait $(n=130)$ & $17.9_{a}$ & $22.2_{a}$ & $21.4 \mathrm{a}$ & $20.0_{a}$ & 26.4 & 25.4 & 0.035 \\
\hline Nonsystemic management $(\mathrm{n}=\mathrm{I77})$ & $22.8_{a}$ & $30.6_{a, b}$ & $32.9_{\mathrm{a}, \mathrm{b}}$ & $30.0_{\mathrm{a}, \mathrm{b}}$ & $40.3_{b}$ & $29.6_{a, b}$ & \\
\hline Systemic treatment $(n=3 \mid 6)$ & $59.3_{a}$ & $47.2_{\mathrm{a}, \mathrm{b}}$ & $45.7_{\mathrm{a}, \mathrm{b}}$ & $50.0_{\mathrm{a}, \mathrm{b}}$ & $33.3_{b}$ & $45 . I_{a, b}$ & \\
\hline
\end{tabular}

Notes: For pairwise comparisons, refer to subscripts (eg, a, b, and c) attached to column percentages. Column percentages in the same row that do not share the same subscript (eg, $X X_{a}$ vs $X X_{b}$ ) are significantly different at $P<0.05$. If they share the same subscript (eg, $X X_{a}$ vs $X X_{a}$ or $X X_{a, b}$ vs $\left.X X_{a}\right)$ then they are not significantly different at $P<0.05$.

Abbreviation: RR-DTC, radioactive iodine refractory differentiated thyroid cancer.

The most commonly administered therapeutic agents for first line were MKIs (ie, sorafenib [37.3\%] or sunitinib [17.7\%]). MKIs were the treatments of choice in the US compared to the EU5 (eg, sorafenib - US: $44.7 \%$ vs EU5: $29.9 \%, P<0.05)$. Cytotoxic agents were also highly prescribed in first line with doxorubicin-based therapy (27.2\%) or cisplatin (12.7\%) as the most common chemotherapies. Chemotherapies were prescribed more in EU5 than in the US (eg, doxorubicin-based therapy - EU5: $42.0 \%$ vs US: $12.6 \%, P<0.05$ ) (Table 5). Table S2 shows the medications broken down by country for the first line.

\section{Adverse events and symptoms of disease burden}

Similar rates of adverse events were reported for patients receiving MKIs and for those receiving chemotherapies (19.9\% vs $22 \%$ ), with diarrhea experienced most commonly for those receiving MKIs (11.2\%), and nausea and vomiting most commonly noted for those receiving chemotherapies (12.6\%) (Table 6).

Symptoms as a result of disease burden were examined by disease state (data not shown). Patients who experienced disease progression in response to treatment (regardless of type) were more likely to report trouble breathing (51.6\% vs $12.9 \%$ ) and bone pain (48.4\% vs $22.4 \%$ ) than those with objective tumor response (both $P$-values $<0.05$ ).

\section{Health care resource utilization}

Compared with patients reporting one disease symptom, patients reporting two or more symptoms had a greater mean number of visits to the treating physician in the prior 12 months (9.37 vs 7.00, $P=0.001$ ). Additionally, patients with two or more symptoms also had a greater mean number of physician visits including outside providers, than those with one symptom ( 12.87 vs $8.96, P<0.001)$. However, those with two or more symptoms did not have more hospitalizations than those with one symptom regardless of reason (Table 7). Similar findings were established by region (data not shown).

Overall, patients who experienced disease progression in response to the latest treatment (regardless of type) were hospitalized more times due to DTC-related complications or treatment-related side effects than patients with an objective tumor response or those who maintained stable disease (both $P_{\mathrm{S}}<0.01$; Table 8). This pattern was similar for the US and EU5 regions (data not shown).

Additionally, health care resource utilization was examined by line of treatment comparing those on the first line of treatment $(\mathrm{n}=248)$ to those on the second through fourth line of treatment ( $\mathrm{n}=68$; data not shown). Those who were on second through fourth lines had a greater mean doctor visits with the current physician than those on first line (11.07 vs $7.44, P<0.001)$. Likewise, those on second through fourth lines had a greater mean doctor visits (for current and other physicians) than those on first line (14.16 vs $10.02, P<0.001)$. Results for mean number of hospitalizations due to DTC disease-associated complications in the past 12 months were marginally higher for second line

Table 3 Current systemic treatment by country for those on systemic treatment $(n=3 \mid 6)$

\begin{tabular}{|c|c|c|c|c|c|c|c|c|}
\hline \multirow{2}{*}{$\begin{array}{l}\text { Current systemic } \\
\text { treatment }\end{array}$} & \multicolumn{7}{|c|}{ Survey country } & \multirow[t]{2}{*}{$P$-value } \\
\hline & $\begin{array}{l}\text { US } \\
(n=159) \\
(\%)\end{array}$ & $\begin{array}{l}\text { UK } \\
(n=34) \\
(\%)\end{array}$ & $\begin{array}{l}\text { Spain } \\
(\mathrm{n}=32) \\
(\%)\end{array}$ & $\begin{array}{l}\text { Italy } \\
(n=35) \\
(\%)\end{array}$ & $\begin{array}{l}\text { Germany } \\
(\mathrm{n}=24) \\
(\%)\end{array}$ & $\begin{array}{l}\text { France } \\
(n=32) \\
(\%)\end{array}$ & $\begin{array}{l}\text { Total } \\
(n=3 \mid 6) \\
(\%)\end{array}$ & \\
\hline Chemotherapies & $16.4_{a}$ & $58.8_{b, c}$ & $21.9_{\mathrm{a}, \mathrm{d}}$ & $65.7_{b}$ & $37.5_{c, \mathrm{~d}, \mathrm{e}}$ & $53 . I_{b, e}$ & 32.3 & $<0.001$ \\
\hline Multikinase inhibitors & $79.2_{a}$ & $41.2_{b}$ & $75.0_{a, d}$ & $17 . I_{c}$ & $54.2_{\mathrm{b}, \mathrm{d}}$ & $46.9 \mathrm{~b}$ & 62.7 & \\
\hline BRAF inhibitors & $4.4_{a}$ & $0.0^{1}$ & $3 . I_{a, b}$ & $17 . I_{b}$ & $8.3_{a, b}$ & 0.0 & 5.1 & \\
\hline
\end{tabular}

Notes: For pairwise comparisons, refer to subscripts (eg, a, b, and c) attached to column percentages. Column percentages in the same row that do not share the same subscript (eg, $X X_{a}$ vs $X X_{b}$ ) are significantly different at $P<0.05$. If they share the same subscript (eg, $X X_{a}$ vs $X X_{a}$ or $X X_{a, b}$ vs $\left.X X_{a}\right)$ then they are not significantly different at $P<0.05$. 
Table 4 Medication by region for those on systemic treatment across all lines $(n=3 \mid 6)$

\begin{tabular}{|c|c|c|c|c|c|c|c|}
\hline \multirow[t]{2}{*}{ Medication type } & \multicolumn{2}{|l|}{ Region } & \multicolumn{5}{|c|}{ Breakdown within EU5 } \\
\hline & $\begin{array}{l}\text { US } \\
(n=\mid 59) \\
(\%)\end{array}$ & $\begin{array}{l}\text { EU5 } \\
(n=\mid 57) \\
(\%)\end{array}$ & $\begin{array}{l}\text { UK } \\
(n=34) \\
(\%)\end{array}$ & $\begin{array}{l}\text { Spain } \\
(\mathrm{n}=32) \\
(\%)\end{array}$ & $\begin{array}{l}\text { Italy } \\
(n=35) \\
(\%)\end{array}$ & $\begin{array}{l}\text { Germany } \\
(\mathrm{n}=24) \\
(\%)\end{array}$ & $\begin{array}{l}\text { France } \\
(\mathrm{n}=32) \\
(\%)\end{array}$ \\
\hline \multicolumn{8}{|l|}{ Cytotoxic chemotherapies } \\
\hline Doxorubicin & 13.8 & 44.6 & 55.9 & 28.1 & 42.9 & 54.2 & 43.8 \\
\hline Cisplatin & 5.7 & 21.0 & 14.7 & 21.9 & 40.0 & 12.5 & 12.5 \\
\hline Docetaxel & 6.9 & 8.3 & 17.6 & 3.1 & 8.6 & 0.0 & 9.4 \\
\hline Paclitaxel & 8.8 & 15.9 & 5.9 & 9.4 & 28.6 & 16.7 & 18.8 \\
\hline Etoposide & 1.9 & 3.2 & 2.9 & 6.2 & 2.9 & 4.2 & 0.0 \\
\hline Other chemotherapy drugs & 0.6 & 5.7 & 0.0 & 0.0 & 14.3 & 4.2 & 9.4 \\
\hline \multicolumn{8}{|l|}{ MKIs } \\
\hline Sorafenib & 52.2 & 34.4 & 29.4 & 50.0 & 20.0 & 37.5 & 37.5 \\
\hline Sunitinib & 26.4 & 18.5 & 11.8 & 37.5 & 11.4 & 20.8 & 12.5 \\
\hline Vandetanib & 19.5 & 3.8 & 2.9 & 0.0 & 5.7 & 4.2 & 6.2 \\
\hline Cabozantinib & 10.7 & 1.9 & 0.0 & 0.0 & 5.7 & 4.2 & 0.0 \\
\hline Pazopanib & 6.9 & 5.1 & 2.9 & 6.2 & 0.0 & 12.5 & 6.2 \\
\hline Axitinib & 5.7 & 0.6 & 0.0 & 3.1 & 0.0 & 0.0 & 0.0 \\
\hline Other MKIs & 2.5 & 2.5 & 2.9 & 9.4 & 0.0 & 0.0 & 0.0 \\
\hline
\end{tabular}

Abbreviations: EU5, five European Union countries: France, Germany, Italy, Spain, and UK; MKI, multikinase inhibitor.

Table 5 MKIs and chemotherapies received by at least $5 \%$ of sample by region for each line of treatment $(n=316)$

\begin{tabular}{|c|c|c|c|c|c|c|c|c|}
\hline \multirow{2}{*}{$\begin{array}{l}\text { Medication } \\
\text { type }\end{array}$} & \multicolumn{2}{|l|}{ First line } & \multicolumn{2}{|c|}{ Second line } & \multicolumn{2}{|c|}{ Third line } & \multicolumn{2}{|c|}{ Fourth line } \\
\hline & $\begin{array}{l}\text { US } \\
(n=I 59) \\
(\%)\end{array}$ & $\begin{array}{l}\text { EU5 } \\
(n=157) \\
(\%)\end{array}$ & $\begin{array}{l}\text { US } \\
(n=I 59) \\
(\%)\end{array}$ & $\begin{array}{l}\text { EU5 } \\
(n=I 57) \\
(\%)\end{array}$ & $\begin{array}{l}\text { US } \\
(n=I 59) \\
(\%)\end{array}$ & $\begin{array}{l}\text { EU5 } \\
(n=I 57) \\
(\%)\end{array}$ & $\begin{array}{l}\text { US } \\
(n=159) \\
(\%)\end{array}$ & $\begin{array}{l}\text { EU5 } \\
(n=157) \\
(\%)\end{array}$ \\
\hline \multicolumn{9}{|c|}{ Cytotoxic chemotherapies } \\
\hline Doxorubicin & 12.6 & 42.0 & 1.9 & 3.8 & 1.3 & 0.0 & 0.0 & 0.0 \\
\hline Cisplatin & 5.0 & 20.4 & 0.6 & 0.0 & 0.0 & 0.6 & 0.0 & 0.0 \\
\hline Docetaxel & 6.3 & 5.7 & 0.0 & 2.5 & 0.6 & 0.0 & 0.0 & 0.0 \\
\hline Paclitaxel & 7.5 & 11.5 & 1.3 & 2.5 & 0.6 & 1.3 & 0.0 & 0.6 \\
\hline \multicolumn{9}{|l|}{ MKIs } \\
\hline Sorafenib & 44.7 & 29.9 & 6.3 & 4.5 & 1.3 & 0.0 & 0.0 & 0.0 \\
\hline Sunitinib & 22.0 & 13.4 & 3.8 & 3.8 & 1.3 & 1.3 & 0.0 & 0.0 \\
\hline Vandetanib & 18.2 & 3.8 & 1.3 & 0.0 & 0.6 & 0.0 & 0.0 & 0.0 \\
\hline Cabozantinib & 5.7 & 1.9 & 3.1 & 0.0 & 1.9 & 0.0 & 0.0 & 0.0 \\
\hline Pazopanib & 5.7 & 2.5 & 1.9 & 2.5 & 0.0 & 0.0 & 0.0 & 0.0 \\
\hline
\end{tabular}

Abbreviations: EU5, five European Union countries: France, Germany, Italy, Spain, and UK; MKI, multikinase inhibitor.

Table 6 Adverse events among patients ever treated with MKls $(n=206)$ and chemotherapies $(n=127)$

\begin{tabular}{lll}
\hline Adverse events & $\begin{array}{l}\text { Chemo } \\
(\mathbf{n = 1} \text { ) 27) }\end{array}$ & $\begin{array}{l}\text { MKI }) \\
(\mathbf{n}=\mathbf{2 0 6}) \mathbf{( \% )}\end{array}$ \\
\hline Any adverse event & 22.0 & 19.9 \\
Nausea and vomiting & 12.6 & 1.0 \\
Loss of appetite & 9.4 & 7.3 \\
Hair loss & 8.7 & 1.5 \\
Diarrhea & 7.9 & 11.2 \\
Fatigue & 7.1 & 8.3 \\
Mouth sores & 7.1 & 6.8 \\
Neuropathy & 5.5 & 2.4 \\
Hematologic toxicity & 4.7 & 0.5 \\
Hand-foot syndrome & 4.7 & 8.7 \\
Weight loss & 4.7 & 1.9 \\
Dysphonia & 2.4 & 1.0 \\
Infections & 2.4 & 0.5 \\
Hypertension & 1.6 & 5.8 \\
\hline
\end{tabular}

Abbreviation: MKI, multikinase inhibitor. through fourth line compared to those for first line ( $0.45 \mathrm{vs}$ $0.17, P=0.053)$.

\section{Discussion}

Treatment patterns and health care resource utilization for patients with RR-DTC are poorly understood. The current study surveyed physicians throughout the US and EU5 to provide important insight into management of patients with the RR-DTC. Interestingly, most patients were diagnosed with Stage II or III DTC; however, nearly half of the patients had Stage IV disease at the time it was deemed RR refractory. It is also important to note that almost half the patients had metastatic disease, with the most common sites of metastases in the bones, lymph nodes, and lungs.

Our results establish that among patients diagnosed with RR-DTC, WW and nonsystemic management options remain 
Table 7 Health care resource utilization by number of symptoms reported as a result of disease burden for those on systemic treatment $(n=316)$

\begin{tabular}{|c|c|c|}
\hline \multirow[t]{2}{*}{ Health care resource utilization } & \multicolumn{2}{|c|}{ Number of symptoms } \\
\hline & $\begin{array}{l}\text { One } \\
\text { symptom } \\
(n=I 58), \\
\text { mean } \pm \text { SD }\end{array}$ & $\begin{array}{l}\text { Two or more } \\
\text { symptoms } \\
(\mathrm{n}=158), \\
\text { mean } \pm \text { SD } \\
\end{array}$ \\
\hline $\begin{array}{l}\text { Times seen patients in the last } \\
12 \text { months }(n=3 \mid 6)\end{array}$ & $7.00 \pm 4.37$ & $9.37 \pm 7.94$ \\
\hline $\begin{array}{l}\text { Total doctor visits (current treating } \\
\text { and other physicians) in the past } \\
12 \text { months ( } n=3 \mid 6)\end{array}$ & $8.96 \pm 6.20$ & $12.87 \pm 12.47$ \\
\hline $\begin{array}{l}\text { Number of times hospitalized for } \\
\text { DTC disease-associated complications } \\
\text { only in the past } 12 \text { months ( } n=168)\end{array}$ & $0.20 \pm 0.79$ & $0.29 \pm 0.71$ \\
\hline $\begin{array}{l}\text { Number of times hospitalized for } \\
\text { DTC treatment-associated side } \\
\text { effects (eg, radiation therapy, } \\
\text { external beam radiation therapy, } \\
\text { chemotherapy, and targeted therapy) } \\
\text { in the past } 12 \text { months ( } n=162 \text { ) }\end{array}$ & $0.1 \mathrm{I} \pm 0.42$ & $0.25 \pm 0.77$ \\
\hline $\begin{array}{l}\text { Number of days hospitalized for DTC } \\
\text { disease-associated complications } \\
\text { collectively }(n=23)\end{array}$ & $7.63 \pm 4.14$ & $6.60 \pm 7.16$ \\
\hline $\begin{array}{l}\text { Number of days hospitalized for DTC } \\
\text { treatment-associated side effects only } \\
\text { (eg, radiation therapy, external beam } \\
\text { radiation therapy, chemotherapy, and } \\
\text { targeted therapy) collectively }(\mathrm{n}=18)\end{array}$ & $5.50 \pm 1.64$ & $8.92 \pm 9.13$ \\
\hline
\end{tabular}

Notes: Not every physician had hospitalization information for each patient. Therefore, there are less responses for number of times hospitalized and number of days hospitalized noted by the sample sizes listed next to the variable names. The sample sizes listed in columns are for the whole sample on systemic treatment. Abbreviation: DTC, differentiated thyroid cancer.

common. Indeed, only about half of those diagnosed with RR-DTC were receiving systemic treatment at the time data were collected, and the majority of patients were on first-line treatment $(78.5 \%)$. These rates were similar by region, with the exception of Germany where significantly lower rates of systemic treatment were observed. Of those on systemic treatment, MKIs were the most commonly prescribed treatment, particularly in the US. Cytotoxic chemotherapies were also commonly prescribed, most notably cisplatin- and doxorubicin-based therapies in EU5. This is an important finding in the context of a recent expert panel that concluded that cytotoxic chemotherapies possessed little clinical benefit for this group of patients. ${ }^{15}$

Overall, patients who experienced disease progression were hospitalized more times due to DTC-related complications or treatment-related side effects than those who maintained stable disease or those with an objective tumor response. It is possible that efficacy and proactive control/ management by experienced physicians may lead to fewer hospitalizations. Additionally, across all regions, those reporting two or more symptoms were more likely to have visited a doctor in the prior 12 months, but no more likely than those with one symptom to be hospitalized. This may suggest effective office management of patients, even those with higher degrees of symptom burden.

Finally, important differences emerged in the treatment of RR-DTC between the US and EU5. Patients in the US were more likely to be treated with MKIs (eg, sorafenib US: $52 \%$ vs EU5: 34\%), whereas patients in the EU5 were

Table 8 Health care resource utilization by response to latest treatment for those on systemic treatment $(n=3 \mid 6)$

\begin{tabular}{|c|c|c|c|}
\hline \multirow[t]{2}{*}{$\begin{array}{l}\text { Health care resource } \\
\text { utilization }\end{array}$} & \multicolumn{3}{|c|}{$\begin{array}{l}\text { Patient's best response to latest } \\
\text { treatment }\end{array}$} \\
\hline & $\begin{array}{l}\text { Objective } \\
\text { tumor } \\
\text { response } \\
(n=I 52), \\
\text { mean } \pm \text { SD }\end{array}$ & $\begin{array}{l}\text { Stable } \\
\text { disease } \\
(n=127), \\
\text { mean } \pm \text { SD }\end{array}$ & $\begin{array}{l}\begin{array}{l}\text { Progressive } \\
\text { disease } \\
(n=37), \\
\text { mean } \pm \text { SD }\end{array}\end{array}$ \\
\hline $\begin{array}{l}\text { Times seen patients in the } \\
\text { last } 12 \text { months }(n=3 \mid 6)\end{array}$ & $8.74 \pm 7.64$ & $7.44 \pm 4.52$ & $8.43 \pm 7.16$ \\
\hline $\begin{array}{l}\text { Total doctor visits } \\
\text { (current treating and } \\
\text { other physicians) in the } \\
\text { past } 12 \text { months ( } \mathrm{n}=316 \text { ) }\end{array}$ & 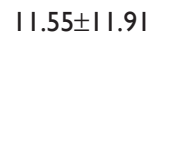 & $10.19 \pm 7.39$ & $10.78 \pm 9.49$ \\
\hline $\begin{array}{l}\text { Number of times } \\
\text { hospitalized for DTC } \\
\text { disease-associated } \\
\text { complications only in the } \\
\text { past } 12 \text { months }(n=168)\end{array}$ & $0.16 \pm 0.71$ & $0.13 \pm 0.39$ & $1.11 \pm 1.28$ \\
\hline $\begin{array}{l}\text { Number of times } \\
\text { hospitalized for DTC } \\
\text { treatment-associated side } \\
\text { effects only (eg, radiation } \\
\text { therapy, external beam } \\
\text { radiation therapy, } \\
\text { chemotherapy, and } \\
\text { targeted therapy) in the } \\
\text { past } 12 \text { months ( } n=162 \text { ) }\end{array}$ & $0.15 \pm 0.50$ & $0.11 \pm 0.36$ & $0.69 \pm 1.45$ \\
\hline $\begin{array}{l}\text { Number of days } \\
\text { hospitalized for DTC } \\
\text { disease-associated } \\
\text { complications only } \\
\text { collectively }(n=23)\end{array}$ & $3.57 \pm 1.13$ & $9.75 \pm 9.00$ & $7.13 \pm 4.22$ \\
\hline $\begin{array}{l}\text { Number of days } \\
\text { hospitalized for DTC } \\
\text { treatment-associated } \\
\text { side effects only (eg, } \\
\text { radiation therapy, } \\
\text { external beam radiation } \\
\text { therapy, chemotherapy, } \\
\text { and targeted therapy) } \\
\text { collectively }(\mathrm{n}=18)\end{array}$ & $5.88 \pm 5.41$ & $8.50 \pm 6.16$ & $10.50 \pm 13.18$ \\
\hline
\end{tabular}

Notes: Not every physician had hospitalization information for each patient. Therefore, there are less responses for number of times hospitalized and number of days hospitalized noted by the sample sizes listed next to the variable names. The sample sizes listed in columns are for the whole sample on systemic treatment.

Abbreviation: DTC, differentiated thyroid cancer. 
more likely to be treated with cytotoxic chemotherapies (eg, cisplatin - EU5: 21\% vs US: 5.7\%). Given that several of the newer MKIs are not widely accessible in all parts of the world, the regional differences in treatment patterns may be related more to drug availability rather than provider preference.

\section{Limitations}

The current study utilized a retrospective medical record abstraction approach, and as such it must be acknowledged that physician respondents selected for study inclusion represent a convenience sample, given that they were recruited from an online panel. Some EU5 countries were represented by a small number of providers. It is therefore possible that the behavior of one provider could have had a substantial impact on the results from their respective country. This is also important when interpreting the health care resource utilization data. For some countries, the data came from a small number providers, and as a result, the charts may have represented patients on certain insurances. Patient's insurance coverage was not examined; therefore, we do not have a good understanding about how the patient's coverage was related to frequency of health care resource utilization and how that may have differed across EU5 countries.

The reliance upon self-reported data collected by physicians from patient charts, as well as some subjective measures reported by physicians, means that recall biases may introduce additional measurement error in the current study. For example, hospitalization data should be interpreted with caution as physicians may not have a record of previous hospitalizations and were therefore relying on patient report. Additionally, there is difficulty in separating patients into groups based on pace of disease progression and cancer-specific symptoms so some with more progressive disease may naturally be in certain management types over others (eg, MKIs vs nonsystemic management). A definition for what constituted RAI refractory disease was not given, and the diagnosis was not confirmed by radiation history. Thus, there may be variations as to what doctors considered RAI refractory disease. Patient end points (eg, time to progression and time to therapy initiation) were also not discussed. Also, because of our recruitment and inclusion criteria, which primarily targeted oncologists, it is possible that our sample consists of patients with RR-DTC with more severe disease, thus limiting generalizability to the entire RR-DTC population.
Finally, we did not perform multivariable analyses on patient data to control for potential covariates as the goal of the study was to provide descriptive data of patient demographics and disease history as well as treatment patterns. As a result, there may be confounding factors that impacted the results.

\section{Future directions}

Further research is needed to gain insight into the varying treatment patterns that emerged among patients with RR-DTC in the US and EU5 and to help inform the development and implementation of universal treatment guidelines. In addition, reasons for discrepancies in treatment for those with RR-DTC (eg, regional availability of medication, physician decision making, patient preference, etc) should be investigated. Finally, there still exists a paucity of research pertaining to the quality of life of patients with RR-DTC and the impact of this disease across broader health outcomes (eg, health care resource utilization). Given that newer agents have recently been approved (eg, lenvatinib), future research should also examine how quality of life is impacted by newer treatment options and which options provide the best quality of life. Future research of newer agents may help inform world treatment guidelines to improve standards of care for this population.

\section{Conclusion}

The current study is an important first step in obtaining a greater understanding of the treatment of RR-DTC globally. Important discrepancies in treatment patterns emerged between regions, providing several possibilities for future investigations. These results can assist in the development and implementation of treatment guidelines, guide resource allocation, and ultimately enhance the care of patients with RR-DTC.

\section{Acknowledgments}

This study was funded by Eisai, Inc. Eisai, Inc. paid Kantar Health for survey design, data collection, data analysis, and manuscript preparation. Marco DiBonaventura and Shu Huang provided support for study design, fielding, or analytic plan and are paid employees of Kantar Health. Errol J Philip provided editorial support for manuscript preparation as a paid consultant to Kantar Health. Gabriel Tremblay provided support for analytic plan and is a paid employee of Eisai, Inc. 


\section{Disclosure}

Eisai, Inc. is the manufacturer of lenvatinib, a drug approved for the treatment of thyroid cancer. Eisai, Inc. paid Kantar Health for survey design, data collection, data analysis, and manuscript preparation. NMF and GRW are paid employees of Kantar Health. CLP and AF are employees of Eisai, Inc. AGG and MHT have no conflicts of interest to report in relation to this work as they volunteered their time for this manuscript. The authors report no other conflicts of interest in this work.

\section{References}

1. American Cancer Society [webpage on the Internet]. Thyroid Cancer 2013. Available from: http://www.cancer.org/Cancer/ThyroidCancer/ DetailedGuide/thyroid-cancer-key-statistics. Accessed May 21, 2013.

2. International Agency for Research on Cancer [webpage on the Internet]. Thyroid Cancer: Estimated Incidence, Mortality and Prevalence for Both Sexes, 2012. 2012. Available from: http://eco.iarc.fr/eucan/Cancer. aspx?Cancer=35. Accessed November 23, 2014.

3. Anderson RT, Linnehan JE, Tongbram V, Keating K, Wirth LJ. Clinical, safety, and economic evidence in radioactive iodine-refractory differentiated thyroid cancer: a systematic literature review. Thyroid. 2013;23(4):392-407.

4. Pellegriti G, Frasca F, Regalbuto C, Squatrito S, Vigneri R. Worldwide increasing incidence of thyroid cancer: update on epidemiology and risk factors. J Cancer Epidemiol. 2013;2013:965212.

5. American Cancer Society. Cancer Facts and Figures 2014. Atlanta: American Cancer Society, Inc.; 2014.

6. Burns WR, Zeiger MA. Differentiated thyroid cancer. Semin Oncol. 2010;37(6):557-566.

7. Jemal A, Siegel R, Ward E, Hao Y, Xu J, Thun MJ. Cancer statistics, 2009. CA Cancer J Clin. 2009;59(4):225-249.
8. McFarland DC, Misiukiewicz KJ. Sorafenib in radioactive iodinerefractory well-differentiated metastatic thyroid cancer. Onco Targets Ther. 2014;7:1291-1299.

9. Brose MS, Nutting CM, Jarzab B, et al. Sorafenib in radioactive iodine-refractory, locally advanced or metastatic differentiated thyroid cancer: a randomised, double-blind, phase 3 trial. Lancet. 2014;384(9940):319-328.

10. Schlumberger M, Tahara M, Wirth LJ, et al. Lenvatinib versus placebo in radioiodine-refractory thyroid cancer. $N$ Engl $\mathrm{J} \mathrm{Med}$. 2015;372(7):621-630.

11. Sacks W, Braunstein GD. Evolving approaches in managing radioactive iodine-refractory differentiated thyroid cancer. Endocr Pract. 2014;20(3):263-275.

12. Worden F. Treatment strategies for radioactive iodine-refractory differentiated thyroid cancer. Ther Adv Med Oncol. 2014;6(6):267-279.

13. Dadu R, Cabanillas ME. Optimizing therapy for radioactive iodinerefractory differentiated thyroid cancer: current state of the art and future directions. Minerva Endocrinol. 2012;37(4):335-356.

14. Sarlis NJ, Gourgiotis L. Unresolved issues, dilemmas and points of interest in thyroid cancer: a current perspective. Hormones (Athens). 2004;3(3):149-170.

15. Brose MS, Smit J, Capdevila J, et al. Regional approaches to the management of patients with advanced, radioactive iodine-refractory differentiated thyroid carcinoma. Expert Rev Anticancer Ther. 2012;12(9):1137-1147.

16. Dingle IF, Mishoe AE, Nguyen SA, Overton LJ, Gillespie MB. Salivary morbidity and quality of life following radioactive iodine for well-differentiated thyroid cancer. Otolaryngol Head Neck Surg. 2013;148(5):746-752.

17. Gallop K, Kerr C, Simmons S, McIver B, Cohen EE. A qualitative evaluation of the validity of published health utilities and generic health utility measures for capturing health-related quality of life (HRQL) impact of differentiated thyroid cancer (DTC) at different treatment phases. Qual Life Res. 2015;24(2):325-338.

18. Kerr C, Fordham B, de Freitas HM, et al. Health state utility valuation in radio-iodine refractory differentiated thyroid cancer (RR-DTC). ISPOR 17th Annual European Congress. Amsterdam: 2014. 


\section{Supplementary materials}

Table SI Medication by metastatic disease status for those on systemic treatment across all lines $(n=316)$

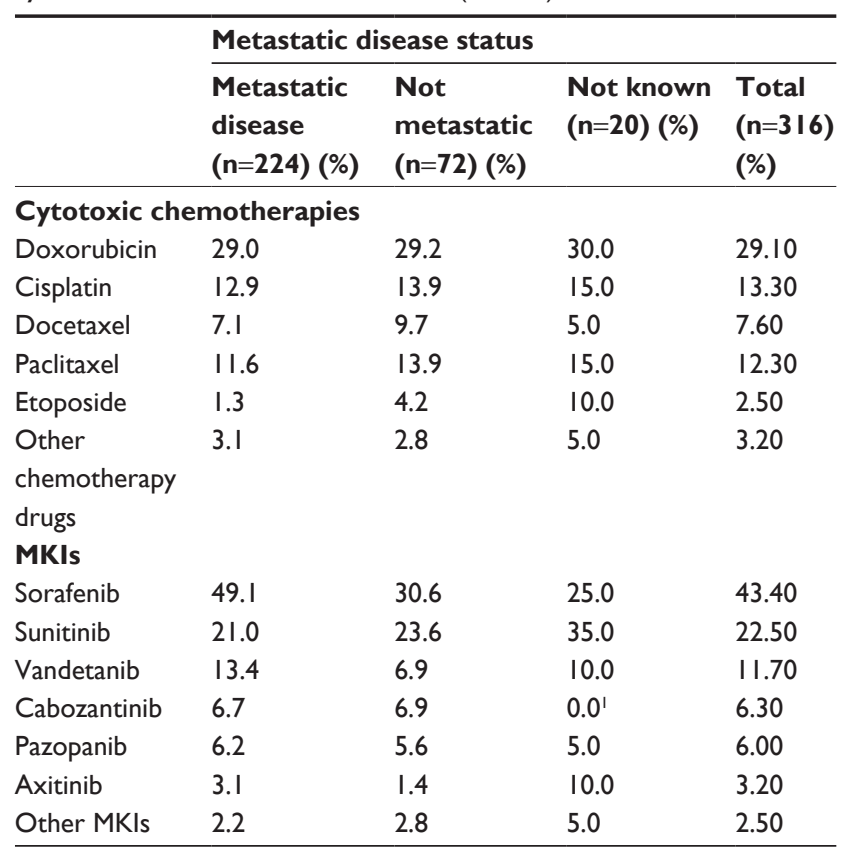

Abbreviation: MKI, multikinase inhibitor.
Table S2 Medication by region for those on systemic treatment for first line only $(n=3 \mid 6)$

\begin{tabular}{|c|c|c|c|c|c|c|}
\hline & \multicolumn{6}{|l|}{ Region } \\
\hline & $\begin{array}{l}\text { US } \\
(n=\mid 59) \\
(\%)\end{array}$ & $\begin{array}{l}\text { UK } \\
(n=34) \\
(\%)\end{array}$ & $\begin{array}{l}\text { Spain } \\
(n=32) \\
(\%)\end{array}$ & $\begin{array}{l}\text { Italy } \\
(\mathrm{n}=35) \\
(\%)\end{array}$ & $\begin{array}{l}\text { Germany } \\
(n=24) \\
(\%)\end{array}$ & $\begin{array}{l}\begin{array}{l}\text { France } \\
(n=32)\end{array} \\
(\%)\end{array}$ \\
\hline \multicolumn{7}{|c|}{ Cytotoxic chemotherapies } \\
\hline Doxorubicin & 12.6 & 52.9 & 28.1 & 40.0 & 45.8 & 43.8 \\
\hline Cisplatin & 5.0 & 14.7 & 21.9 & 40.0 & 8.3 & 12.5 \\
\hline Docetaxel & 6.3 & 8.8 & 3.1 & 5.7 & 0.0 & 9.4 \\
\hline Paclitaxel & 7.5 & 2.9 & 6.2 & 25.7 & 4.2 & 15.6 \\
\hline Etoposide & 1.9 & 2.9 & 6.2 & 0.0 & 4.2 & 0.0 \\
\hline Other & 0.6 & 0.0 & 0.0 & 14.3 & 4.2 & 9.4 \\
\hline \multicolumn{7}{|l|}{ chemotherapy } \\
\hline \multicolumn{7}{|l|}{ drugs } \\
\hline \multicolumn{7}{|l|}{ MKIs } \\
\hline Sorafenib & 44.7 & 26.5 & 43.8 & 20.0 & 25.0 & 34.4 \\
\hline Sunitinib & 22.0 & 8.8 & 25.0 & 8.6 & 12.5 & 12.5 \\
\hline Vandetanib & 18.2 & 2.9 & 0.0 & 5.7 & 4.2 & 6.2 \\
\hline Cabozantinib & 5.7 & 0.0 & 0.0 & 5.7 & 4.2 & $0.0^{1}$ \\
\hline Pazopanib & 5.7 & 2.9 & 0.0 & 0.0 & 4.2 & 6.2 \\
\hline Axitinib & 2.5 & 0.0 & 0.0 & 0.0 & 0.0 & 0.0 \\
\hline Other MKIs & 1.9 & 2.9 & 9.4 & 0.0 & 0.0 & 0.0 \\
\hline
\end{tabular}

Abbreviation: MKI, multikinase inhibitor.

\section{Publish your work in this journal}

Cancer Management and Research is an international, peer-reviewed open access journal focusing on cancer research and the optimal use of preventative and integrated treatment interventions to achieve improved outcomes, enhanced survival and quality of life for the cancer patient. The journal welcomes original research, clinical \& epidemiological

\section{Dovepress}

studies, reviews \& evaluations, guidelines, expert opinion \& commentary, case reports \& extended reports. The manuscript management system is completely online and includes a very quick and fair peerreview system, which is all easy to use. Visit http://www.dovepress.com/ testimonials.php to read real quotes from published authors. 